\title{
Análise das trajetórias das exportações de Brasil e Argentina no comércio internacional do complexo soja (1990 - 2018)
}

\author{
Maiara Thaís Tolfo Gabbi ${ }^{1}$ \\ Nilson Luiz Costa ${ }^{2}$ \\ Gabriel Nunes de Oliveira ${ }^{3}$ \\ Elisangela Gelatti ${ }^{4}$ \\ Angélica Cristina Rhoden ${ }^{5}$
}

\begin{abstract}
Resumo
O estudo teve como objetivo analisar as trajetórias de exportações de Brasil e Argentina no comércio internacional de soja em grãos, farelo de soja e óleo de soja entre 1990 a 2018. Para tal utilizou-se um modelo econométrico de taxa de crescimento através da coleta de dados secundários no Department of Agriculture (USDA) para o período de 1990 a 2019. Os resultados mostram de forma comparada que a Argentina apresentou uma taxa de crescimento anual maior nas exportações de farelo de soja $7,05 \%$ e óleo de soja $6,16 \%$, enquanto a taxa geométrica de crescimento das exportações para soja em grãos representou 5,15\%, no consumo doméstico a Argentina obteve uma taxa de crescimento anual de 7,22\%. Já o Brasil, obteve uma taxa de crescimento maior nas exportações de soja em grãos $12,12 \%$, enquanto as exportações de farelo de soja e óleo de soja representaram respectivamente, $1,97 \%$ e $1,92 \%$, e no consumo doméstico obteve uma taxa geométrica de crescimento de $3,91 \%$. Por fim, o modelo econométrico de taxa de crescimento permitiu analisar o cenário de exportações de Brasil e Argentina e concluir que nas últimas décadas a Argentina se destacou pelo aumento nas exportações de farelo e óleo de soja, enquanto o Brasil pelo aumento nas exportações de soja em grãos, o que evidencia trajetórias de exportação antagônicas.
\end{abstract}

Palavras Chaves: Complexo Soja; Exportações; Brasil; Argentina.

\section{Analysis of the export trajectories of Brazil and Argentina in the international trade of the soy complex (1990 - 2018)}

\begin{abstract}
The study aimed to analyze the export trajectories of Brazil and Argentina in the international trade of soybeans, soybean meal and soybean oil between 1990 to 2018. For that, an econometric model of growth rate was used through the collection of secondary data at the Department of Agriculture (USDA) for the period from 1990 to 2019. The results show in a comparative way that Argentina presented a higher annual growth rate in exports of soybean meal $7.05 \%$ and $6.16 \%$ soybean oil, while the geometric growth rate of soybean grain exports represented $5.15 \%$, in domestic consumption Argentina obtained an annual growth rate of $7.22 \%$. Brazil, on the other hand, had a higher growth rate in exports of soybeans in grains $12.12 \%$, while exports of soybean meal and soybean oil represented $1.97 \%$ and $1.92 \%$, respectively, and in domestic consumption. a geometric growth rate of $3.91 \%$. Finally, the econometric model of growth rate made it possible to analyze the export scenario of Brazil and Argentina and conclude that in recent decades Argentina has stood out for the increase in soybean meal and oil exports, while Brazil for the increase in soybean exports in grains, which shows antagonistic export trajectories.
\end{abstract}

Keywords: Soy Complex; Exports; Brazil; Argentina.

${ }^{1}$ Mestre em Agronegócios (PPGAGR/UFSM). Orcid: 0000-0001-9407-1587. maiaratolfo@gmail.com

2 Doutor em Ciências Agrárias. Coordenador do Programa de Pós-Graduação em Agronegócios da Universidade Federal de Santa Maria (PPGAGR/UFSM). Orcid: 0000-0003-2000-1521. nilson.costa@ufsm.br

${ }^{3}$ Doutor em Extensão Rural. Professor da Universidade Federal de Santa Maria (UFSM), Campus de Palmeira das Missões. Orcid: 0000-0003-0620-4955. ambientalgnu@uol.com.br

${ }^{4}$ Doutoranda no Programa de Pós-Graduação em Economia na Escola Superior de Agricultura "Luiz de Queiroz" da Universidade de São Paulo. Orcid: 0000-0002-1388-0460. elisangelagelatti@hotmail.com

${ }^{5}$ Doutoranda em Extensão Rural no Programa de Pós-Graduação em Extensão Rural da Universidade Federal de Santa Maria (PPGExR/UFSM). Orcid: 0000-0002-7296-4031. angelicarhoden.iff@gmail.com 


\section{Introdução}

A disseminação do cultivo da soja no Brasil e na Argentina os tornaram países influentes no comércio internacional do complexo soja, em especial nos setores de soja em grãos, farelo de soja e óleo de soja, os quais apresentam maior representatividade na pauta produtora e exportadora. E por tanto, Brasil representa $36,42 \%$ do total produzido e $50,96 \%$ do total exportado no mundo e a Argentina representa $15,69 \%$ do total produzido e 5,50\% do total exportado no mundo na safra de 2019/20 (USDA, 2020).

A representatividade econômica que a cultura sojícola exerceu, historicamente, na economia brasileira e argentina, permitiu o crescimento da exportação do complexo soja de modo competitivo. Dessa forma, os dois países, vem fornecendo ao mercado mundial, produtos e processos de qualidade e a preços competitivos (USDA, 2020; CALDARELLI et al., 2009).

Destaca-se que, no complexo soja, há diferentes estágios, e dessa forma, dinâmicas e tendências individualizadas para cada item comercializado no comércio internacional. Assim, este estudo visa identificar comparativamente, quais as tendências escolhidas pelo Brasil e a Argentina, uma vez que, nos últimos anos, o Brasil intensificou as exportações de soja em grãos, enquanto as exportações de farelo e óleo, relativamente, pouco cresceram. Diferentemente da Argentina, em que, nota-se uma intensificação nas exportações de farelo e óleo de soja (USDA, 2020).

Deste modo, o estudo se propõe a analisar as trajetórias de exportações de Brasil e Argentina no comércio internacional de soja em grãos, farelo de soja e óleo de soja, para o período de 1990 a 2018. Para isso, utilizou-se o modelo econométrico de taxa de crescimento calculado a partir das exportações de soja em grãos, farelo e óleo de soja de Brasil e Argentina para o período de 1990 a 2018. Ainda, este estudo busca contribuir com o debate sobre a inserção do Brasil no comércio internacional, visando que o país possua melhores condições e estratégicas de competir de forma mais estruturada com seus concorrentes no mercado mundial da soja, a partir de exportações de produtos com maior valor agregado.

A pesquisa está segmentada em cinco seções, considerando a introdução. A segunda apresenta a metodologia utilizada para alcançar o objetivo proposto e a terceira seção aborda os resultados e discussões. A quarta seção elenca as conclusões desse estudo e por fim, a quinta seção apresenta as referências bibliográficas. 


\section{Metodologia}

Nesta seção se apresenta o Modelo Econométrico de Taxa de Crescimento aplicado na pesquisa. Assim para identificar as tendências de exportações de Brasil e Argentina no comércio internacional, foi obtido as séries dados de produção, exportação, esmagamento, consumo doméstico e importação do farelo de soja, óleo de soja e soja em grão no US Department of Agriculture (USDA) para o período de 1990 a 2019 e a partir disso, realizado um modelo econométrico de taxa de crescimento log-linear. Esse modelo é utilizado pelos autores Santana (2003) e Gujarati (2006) por meio da seguinte estimação:

$$
\ln P_{t i}=\alpha+\beta_{1} \text { Tend }+\varepsilon
$$

em que:

$\ln P_{t i}$ é o logaritmo natural das variáveis (produção, exportação, esmagamento, consumo doméstico e importação do farelo de soja, óleo de soja e soja em grão) do país (Brasil, Argentina) no tempo $t$, sendo $i$ = farelo de soja, óleo de soja e soja em grão;

$\alpha$ é a constante da regressão;

$\beta_{1}$ é o coeficiente associado à tendência (Tend), cujo antilogaritmo representa o crescimento médio em termos percentuais, no valor do $P_{t i}$, para cada aumento de uma unidade na variável tempo.

Tend é o coeficiente de tendência da regressão

$\varepsilon$ é o termo de erro aleatório;

Nessa metodologia é utilizado o teste $\mathrm{F}$ como critério de significância estatística do resultado econométrico e adotou-se o nível de probabilidade de $5 \%$. Além disso, foi calculado o antilogaritmo das séries anuais de dados, apresentado pelas equações 6 e 7 e orientações metodológicas contidas em Santana (2003) e Gujarati e Porter (2011):

$$
\begin{aligned}
& r=\left[\left(e^{b}\right)-1\right] \times 100 \\
& r=\left[\left(2,718281828459045235360287^{b}\right)-1\right] \times 100
\end{aligned}
$$




\section{Resultados e discussões}

Nesta seção se apresenta os resultados e discussões da análise das trajetórias das exportações do Brasil e da Argentina no comércio internacional de soja em grão, farelo de soja e óleo de soja. A seção está dividida em duas partes, a primeira apresenta a trajetória e a evolução das exportações do Brasil e da Argentina e a segunda exibe as taxas de crescimento da produção, exportação, esmagamento, consumo doméstico e importação do farelo de soja, óleo de soja e soja em grão entre Brasil e Argentina.

\subsection{Análise da trajetória e da evolução das exportações de farelo e óleo de soja e soja em grãos do Brasil e da Argentina}

A oleaginosa soja, conhecida cientificamente como Glycine max (I.) Meer., originou na Ásia Oriental, e cultivada com objetivos comerciais, transformou-se em importante fonte de proteína e óleo vegetal, se tornando a base na fabricação de rações para a alimentação de aves, suínos e bovinos, e em razão dos avanços da indústria, tornou-se ingrediente predominante nos alimentos processados em geral (COSTA; SANTANA, 2013; USDA, 2016).

O seu cultivo passou por importantes mudanças ao longo do tempo, como o crescimento das áreas cultivadas, modernização e reestruturação da cadeia produtiva, bem como em infraestrutura, instituições de apoio, políticas macroeconômicas e setoriais, avanços em tecnologia e investimentos em pesquisa (COSTA; SANTANA, 2013; SAMPAIO et al, 2012).

As transformações do setor, aliado a importância alimentar da oleaginosa para animais e para a humanidade, levaram ao crescimento da produção consideravelmente alto nos últimos anos, e tornou-a, como quarta principal cultura produzida globalmente, em volume, onde mais de $85 \%$ da produção são processados. É através do esmagamento, que se obtém o farelo e óleo de soja. O farelo é utilizado principalmente como ração animal pelo seu conteúdo proteico, enquanto o óleo é utilizado para a produção de alimentos e, mais recentemente, para outros usos industriais e biodiesel (USDA, 2016). 


\subsubsection{Análise das trajetórias das exportações do complexo soja no Brasil e na Argentina}

A soja e seus derivados representam produtos que possuem elevada negociação, e respondem por mais de $10 \%$ do valor total do comércio agrícola global (USDA, 2016). O comércio global de soja e produtos de soja aumentou rapidamente desde o início da década de 1990. Além disso, a renda dos países em desenvolvimento cresceu nas últimas décadas, o que reflete na ampliação do consumo de alimentos, e consequentemente na necessidade de mais produtos e derivados da soja (RICHARDSON, 2008).

Devido ao aumento da demanda mundial e a dependência da renda desse mercado, os países buscam cada vez mais ampliar a produtividade no objetivo de alcançar novos mercados. Dentro desta ótica, Brasil e Argentina são países que ao longo dos anos se tornaram referência no mercado da soja, devido à forte participação no comércio internacional. $E$, apesar de, ambos os países produzirem soja, os mesmos se organizaram de maneiras diferentes para o mercado internacional. Essa diferença pode ser vista na Figura 1, Figura 2 e na Figura 3, quando comparadas demonstram que Brasil intensificou as exportações em soja em grãos e a Argentina em óleo e farelo de soja.

A Figura 1 mostra as exportações de soja em grãos no Brasil e Argentina nas safras de 1989/90 a 2017/18. Observa-se que houve um crescimento maior das exportações do Brasil, enquanto a Argentina manteve-se constante nas exportações.

Analisando-se a Figura 1, no ano/safra de 1989/1990 as exportações brasileiras de soja em grão foram de 3,93 milhões de toneladas e no ano/safra de 2017/2018 alcançou 72,3 milhões de toneladas. Na Argentina no ano/safra 1980/1990 as exportações de soja em grão foram de 2,96 milhões de toneladas e no ano safra de 2017/2018, foram de 8 milhões de toneladas. Essa estrutura de exportações da soja em grãos consolidada no comércio internacional, encontra-se com os estudos dos autores Figueiredo e Santos (2005), uma vez que estes revelam que, nas exportações de soja em grãos, o Brasil concorre com os Estados Unidos no comércio internacional e nos derivados de óleo e farelo de soja, concorre com a Argentina. 
Figura 1 - Exportações de soja em grão do Brasil e Argentina: de 1989/90 a 2017/18 (1.000 MT¹)

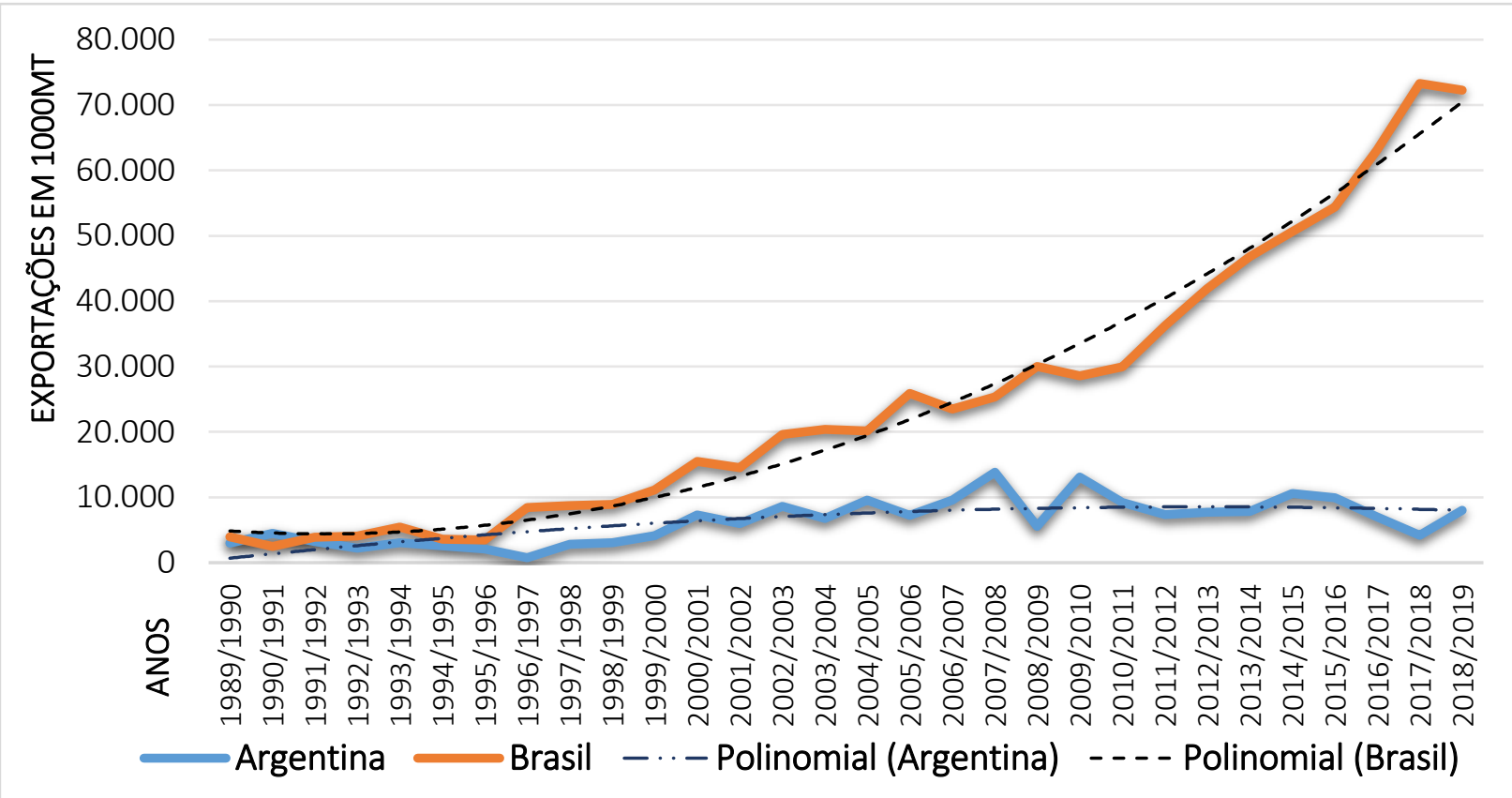

Fonte: Elaboração própria com base em USDA (2020)

Na Figura 2 revela-se as exportações brasileiras e argentinas de farelo de soja no período de 1989/90 a 2017/18. Observa-se que houve um crescimento maior das exportações de farelo de soja por parte da Argentina, enquanto no Brasil ocorreu um crescimento moderado.

Figura 2 - Exportações de farelo de soja do Brasil e da Argentina: 1989/90 a 2017/18 em 1000MT

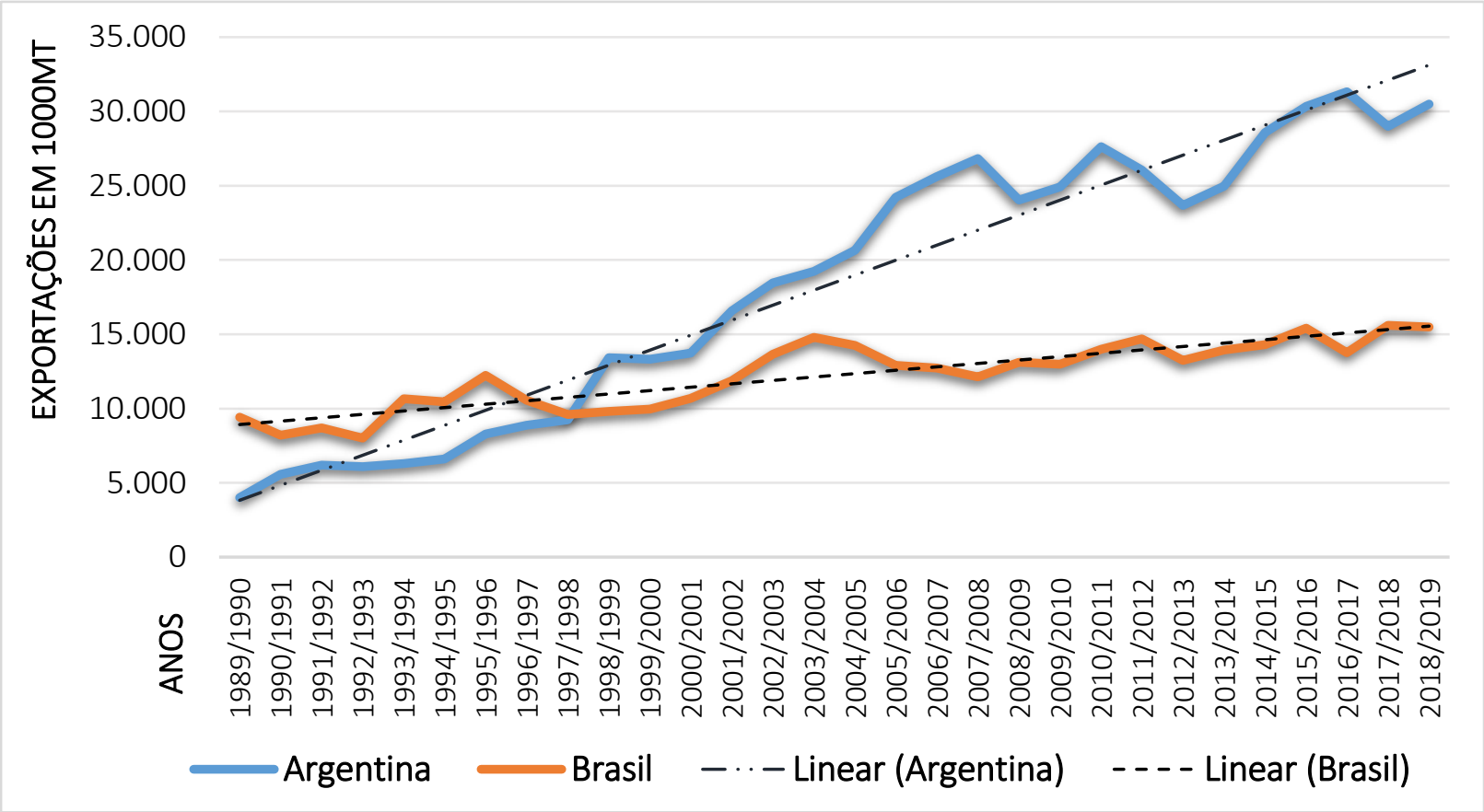

Fonte: Elaboração própria com base em USDA (2020)

\footnotetext{
1 Toneladas Métricas.
} 
A Figura 3 mostra as exportações de óleo de soja no Brasil e Argentina nas safras de 1989/90 a 2017/18. Observa-se que houve um crescimento maior das exportações de óleo de soja por parte da Argentina, ao passo que o Brasil se manteve constante nas exportações. Analisando-se a Figura 3, no ano/safra de 1989/1990 as exportações brasileiras de óleo de soja foram de 660 mil toneladas e no ano/safra de 2017/2018 foram 1,48 milhões de toneladas. Na Argentina no ano/safra 1980/1990 as exportações de óleo de soja foram de 1,12 milhões de toneladas e no ano safra de 2017/2018 alcançou 4,67 milhões de toneladas.

Figura 3 - Exportações de óleo de soja do Brasil e da Argentina: 1989/90 a 2017/18 em 1000MT

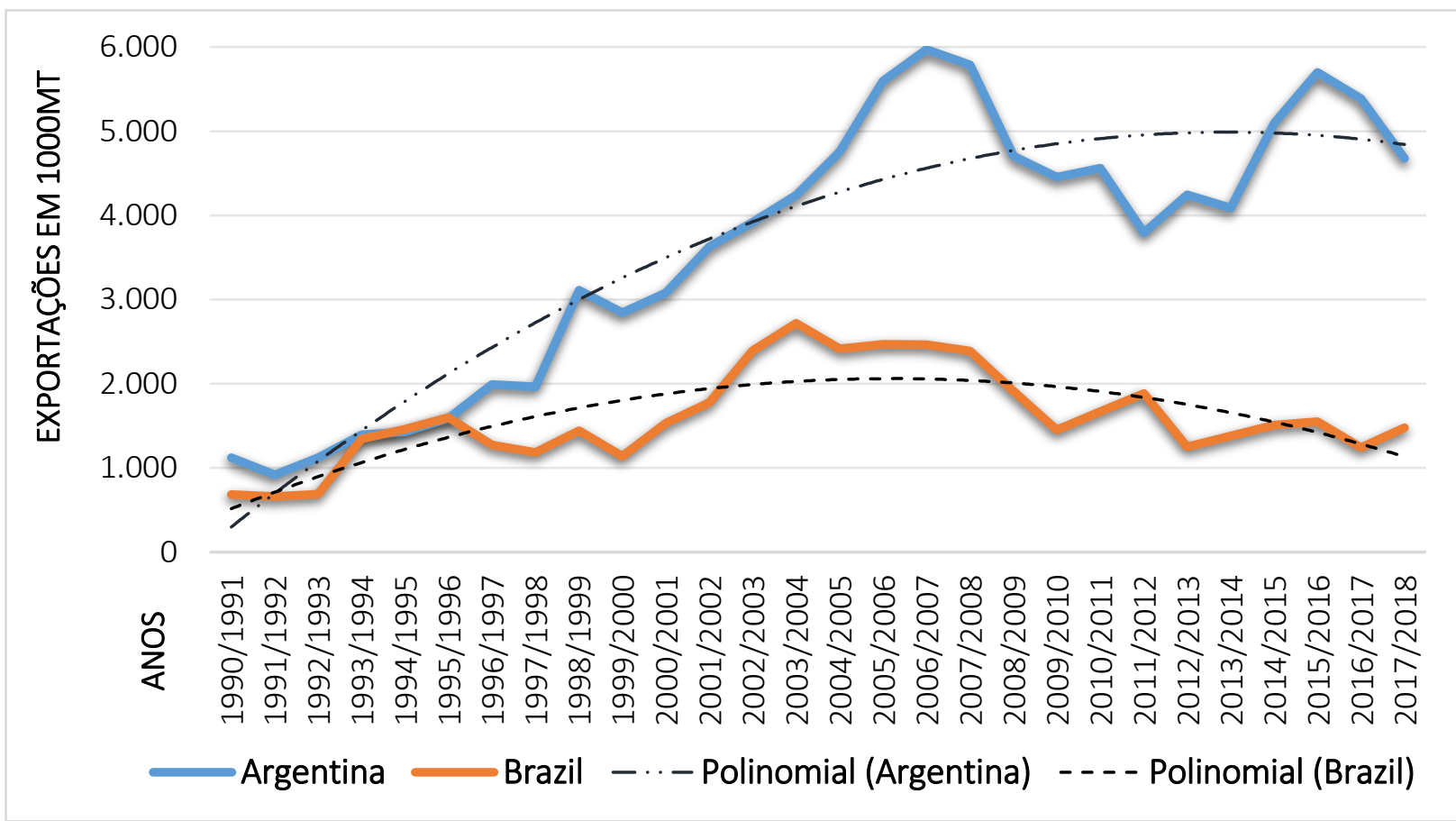

Fonte: Elaboração própria com base em USDA (2020)

Enquanto a soja em grão brasileira contabilizada em 2017 representou 42,79\% das exportações totais do produto, o Farelo de soja representou apenas $21,33 \%$ e o óleo de soja 11,3\%. Essa situação mostra que o Brasil destina a maior parte de seu produto para exportação in natura, em detrimento das exportações de processados como o óleo de soja e o farelo de soja.

Na Argentina, o farelo de soja contabilizado em 2017 representou 48,56\% e o óleo de soja $47,86 \%$ do total das exportações, ao passo que a soja em grão representou apenas $4,76 \%$. Estes aspectos, determinam o país como exportador principalmente de processados, enquanto a soja in natura é parte pequena desse mercado (USDA, 2020). 
As figuras 1, 2 e 3 demonstram o quanto o Brasil e a Argentina ampliaram suas exportações no período analisado e evidenciaram posições antagônicas. Assim na próxima subseção é apresentada a evolução das exportações do complexo soja de Brasil e Argentina.

\subsection{Evolução das exportações do complexo soja do Brasil e da Argentina}

O Brasil elevou produção e exportação de farelo de soja, óleo de soja e principalmente de soja em grão. Desde então, nos últimos anos o Brasil lidera as exportações do comércio mundial de soja em grão, farelo de soja e óleo de soja, junto com Estados Unidos e Argentina (USDA, 2020). No mercado doméstico, o complexo soja brasileiro lidera as exportações dos produtos agropecuários, em 2018 participou em 40,23\% das exportações totais agropecuárias (AGROSTAT, 2020). A soja em grão representou $81,12 \%$ das exportações do complexo soja, em seguida vem as exportações de farelo de soja com $16,37 \%$ das exportações do complexo soja e por último o óleo de soja com 2,51\% das exportações do complexo soja brasileiro (AGROSTAT, 2020).

$\mathrm{Na}$ Figura 4, se exibe os principais exportadores de soja em grãos no mundo no período de 1990 a 2019. Constata-se Brasil e Estados Unidos detém a maior parcela de exportação de soja em grãos no comércio internacional, e assim como na produção, na exportação obtiveram uma tendência crescente ao longo do período, enquanto o restante dos países que participam do comércio internacional representam uma parcela menor das exportações de soja em grãos no mundo, bem como obtiveram um crescimento moderado, representado por patamares semelhantes de exportação ao longo do período.

Nota-se que nos últimos anos, o Brasil tem liderado as exportações de soja em grãos no comércio internacional, no ano safra de 1989/90 exportava 3,93 milhões de toneladas e em 2018/19 alterou-se o volume exportado ampliando intensamente as exportações para 81 milhões de toneladas, e dessa forma representou um aumento de aproximadamente 20 vezes no volume exportado de soja em grãos. Já Estados Unidos tem sido o segundo maior exportador de soja em grãos, e ampliou sua participação no comércio internacional da soja em grãos em 3 vezes, alterando se as exportações de 1989/90 em 16,93 milhões de toneladas para 2018/19 em 51,71 milhões de toneladas de soja em grãos exportadas. 
Figura 4 - Principais países exportadores mundiais de soja em grão (1000MT) de 1990 a 2019

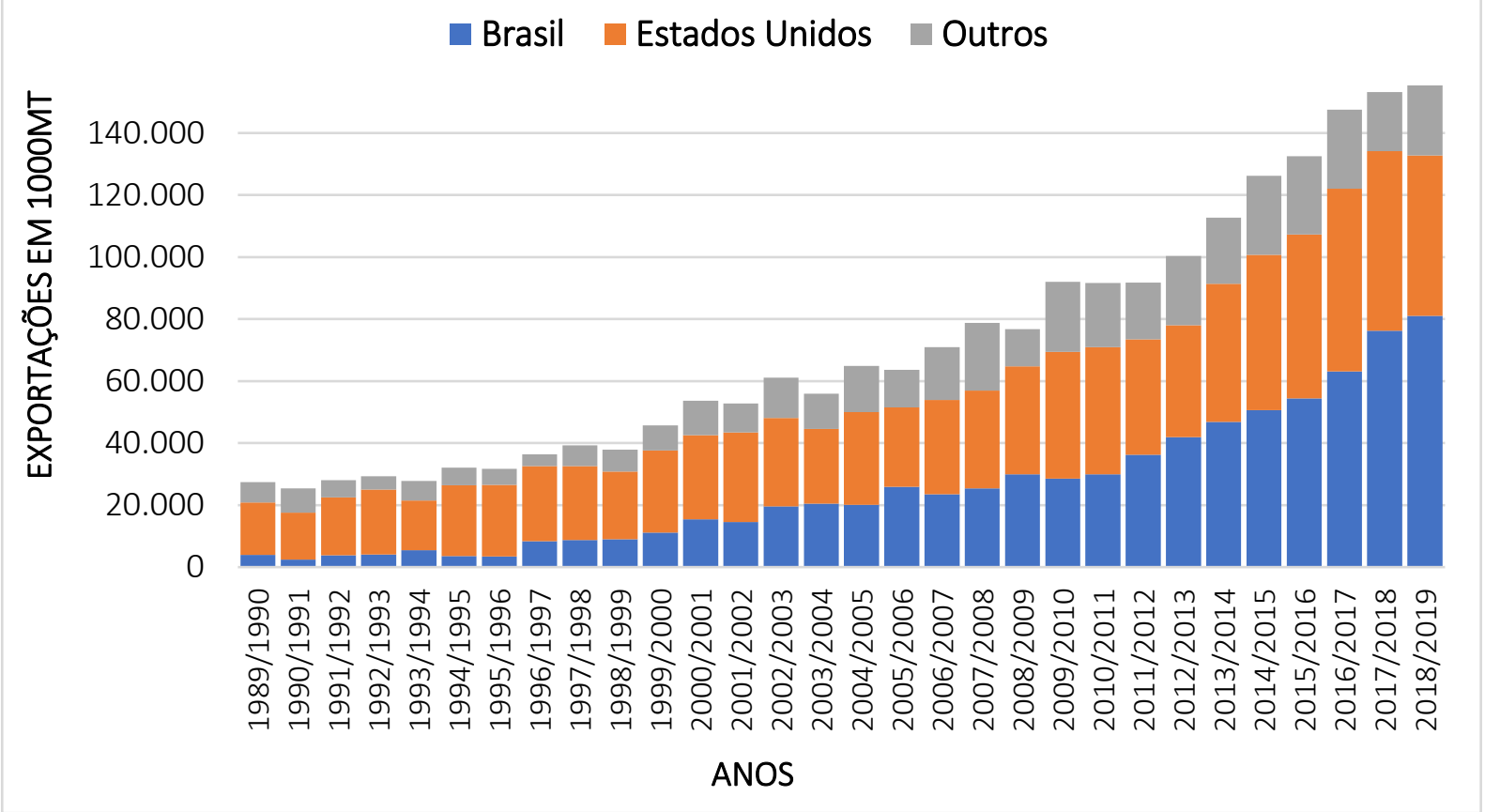

Fonte: Organização do autor com base em USDA (2020).

Na Figura 5, mostra-se a produção, exportação e esmagamento de soja em grãos no Brasil no período de 1989/90 a 2018/19. Constata-se que houve uma tendência de crescimento tanto na produção, quanto na exportação e esmagamento da soja em grãos no período, no entanto em proporção maior por parte da produção e da exportação de soja no Brasil. A produção de soja obteve um crescimento de 5 vezes ao longo do período de análise, alterou-se o cenário inicial de produção representado por 20,34 milhões de toneladas produzidas em 1989/90 para 116,5 milhões de toneladas produzidas em 2018/19. Da mesma forma, as exportações de soja em grãos também obtiveram patamares semelhantes de expansão, já apresentados na Figura 4.

No entanto, o esmagamento doméstico de soja em grãos obteve um crescimento leve, quando comparadas ao aumento na produção e exportação do produto no mesmo período. 0 esmagamento doméstico obteve um crescimento de 2 vezes e representou um aumento de volume esmagado de 15,75 milhões de toneladas em 1989/90 para 42,7 milhões de toneladas esmagadas em 2018/19. Dado o grande aumento da produção de soja em grãos, o Brasil ao longo dos anos obtinha capacidade suficiente de atender a uma maior demanda de soja em grãos para processamento, neste caso, há margem para ampliar a produção de farelo e óleo de soja internamente. 
Figura 5 - Produção, exportação e esmagamento de soja em grão no Brasil, no período de $1989 / 90$ a $2018 / 19$

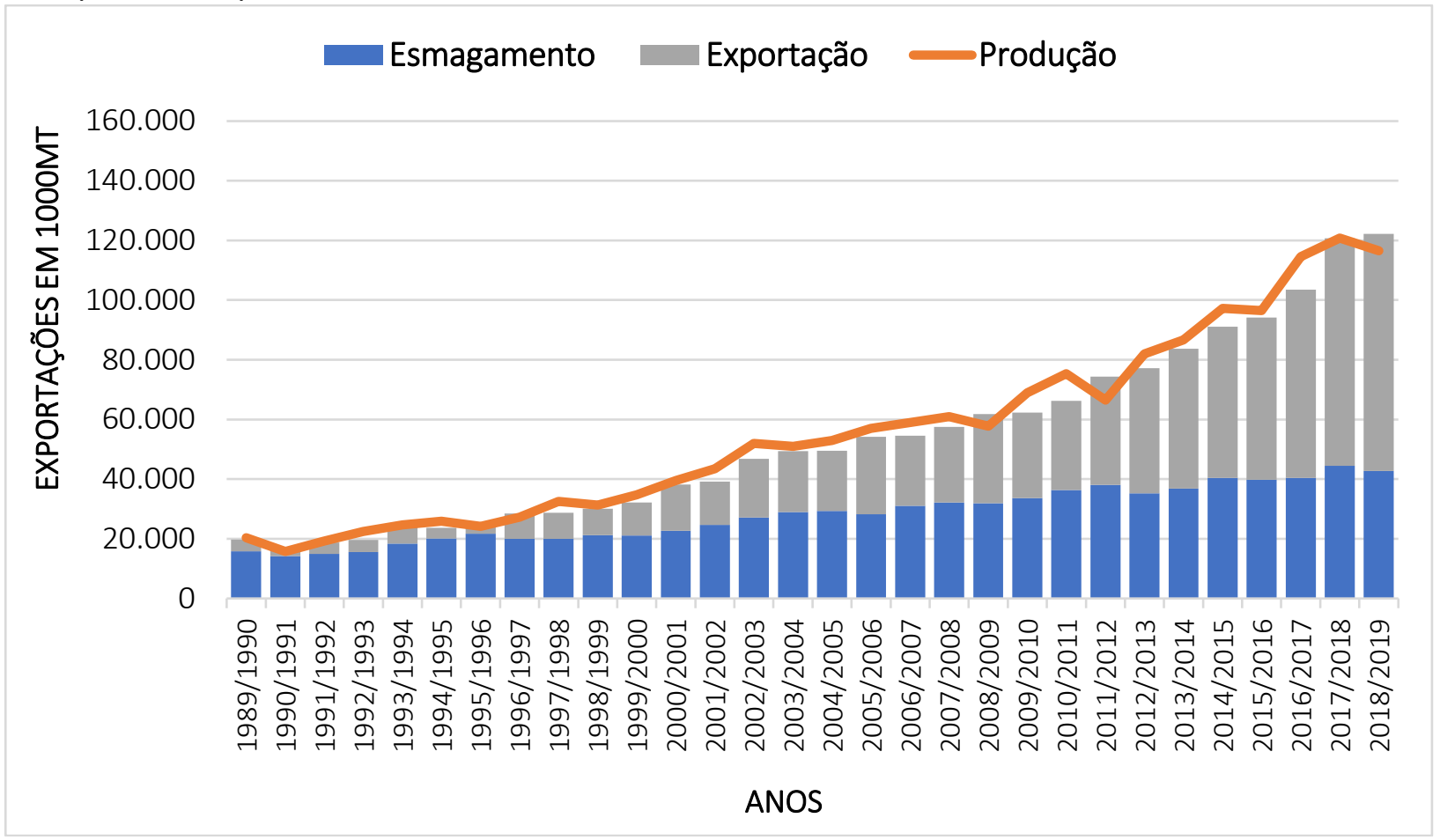

Fonte: Organização do autor com base em USDA (2020).

A expansão da soja na Argentina faz parte de um aumento global da soja no mercado. Segundo dados da Cámara de la Industria Aceitera de la República Argentina (CIARA, 2020), a Argentina é o terceiro produtor e exportador mundial de soja depois do Brasil e dos Estados Unidos, e concentra parte dessa participação na produção e exportação de óleo e farinha desta oleaginosa. A soja para a Argentina é o principal complexo exportador, na produção primária, cerca de $75 \%$ é destinada a industrialização, e o restante exportado in natura para o mercado externo. Da produção total do óleo de soja bruto, cerca de $67 \%$ é destinado à exportação, $27 \%$ para a produção de biodiesel e o restante para refino (consumo doméstico, ou outras indústrias) (CIARA, 2020).

Argentina consolidou as agroindústrias de processamento devido algumas medidas em relação a taxas mais elevadas sobre a soja em grão em torno de $23 \%$ e $20 \%$ para derivados (CIARA, 2020). O US department of agriculture em março de 2008 no relatório "Soybeans and oil crops" cita o domínio recorrente da Argentina nas exportações mundiais de farelo e óleo de soja, devido ao uso doméstico modesto e pelas taxas diferenciadas de exportação, o que torna competitivo processar a soja. A Argentina tributa as exportações da soja em grão a uma taxa maior que as exportações de farelo e óleo de soja, o que explica a maior demanda por parte das processadoras domésticos. 
A Figura 6 apresenta a produção, esmagamento e exportação de soja em grãos na Argentina no período de 1989/1990 a 2018/2019. Observa-se que no início do período a produção, esmagamento e exportação apresenta-se constante, a partir de 1996/97 houve um crescimento considerável da produção de soja, e dessa forma impactou sobre a ampliação do esmagamento e das exportações de soja em grãos, no entanto identifica-se também que nos últimos anos do período as exportações de soja em grãos sofreram uma queda, enquanto o esmagamento de soja em grãos obteve uma leve ampliação.

A produção de soja em grãos passou de 10,75 milhões de toneladas em 1989/1990 para 55 milhões de toneladas em 2018/2019, o esmagamento de soja em grãos ampliou de 6,24 milhões de toneladas em 1989/1990 para 43 milhões de toneladas esmagadas em 2018/2019, enquanto a soja em grãos iniciou as exportações com 4,46 milhões de toneladas em 1989/1990 e em 2018/2019 tem exportado 6,3 milhões de toneladas. Para fins de impacto, a soja esmagada representa $78,18 \%$ de toda a soja produzida na Argentina.

Figura 6 - Produção, esmagamento e exportação de soja em grão da Argentina de 1989/1990 a $2018 / 2019$

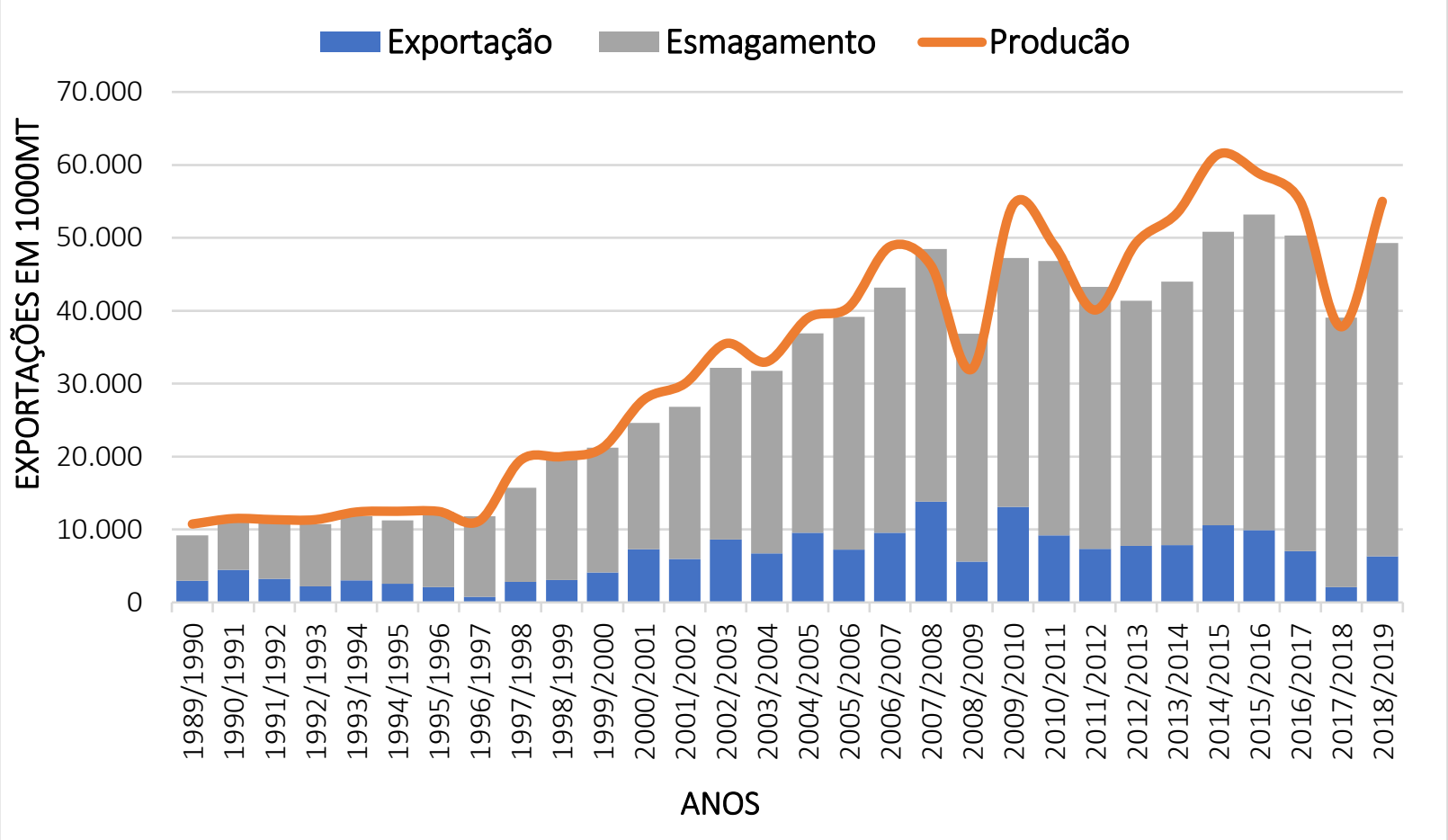

Fonte: Organização do autor com base em USDA (2020).

O crescimento da produção de soja em grãos na Argentina foi de 5 vezes maior, do esmagamento de soja foi de 7 vezes maior, ao passo que o crescimento das exportações de soja em grãos representou apenas 1 vez maior. Desta forma permite-se verificar que a ampliação da 
produção da soja levou a ampliação do esmagamento doméstico de soja em grãos, devido ao alto potencial de processamento de soja Argentino, enquanto a soja em grãos pouco representou sobre o total de produção de soja na Argentina.

O beneficiamento tem, de fato, acompanhado o crescimento da produção de soja na Argentina (CIARA, 2020). Embora, no início da década de 1990, a indústria apresentou certa ociosidade, o aumento da produção foi reduzindo a inatividade, bem como estimulando a construção de novas unidades e a ampliação das existentes. Diante disso, o número de unidades chegou a 44, e a capacidade das fábricas cresceu 205\% de 1995 a 2011, atingindo praticamente 175 mil toneladas/dia (HINRICHSEN, 2013). O biodiesel de soja também tem ganhado importância no cenário recente, impulsionado a produção de soja na Argentina.

Na Figura 7, apresenta-se os maiores países esmagadores de soja em grãos no mundo no período de 1990 a 2019. Observa-se que os maiores países são China, Estados Unidos, Argentina e Brasil, ainda esses países obtiveram uma tendência crescente de esmagamento de soja no período de 1989/90 a 2018/19. O país que mais ampliou seu esmagamento doméstico foi a China, e alterou o cenário inicial de 3,69 milhões de toneladas esmagadas em 1989/90 para 92,5 milhões de toneladas esmagadas em 2018/19, resultando a um aumento de 25 vezes maior no esmagamento de soja em grãos.

Entre os demais países representativos no esmagamento de soja em grãos estão ainda Estados Unidos, Argentina e Brasil. Os Estados Unidos esmagaram 31,18 milhões de toneladas em 1989/90 e obteve uma elevação para 56,6 milhões de toneladas esmagadas em 2018/19, resultando a um aumento de 1 vez mais. Enquanto a Argentina obteve um aumento de 2 vezes mais no esmagamento, alterando o cenário inicial de 15,75 milhões de toneladas esmagadas em 1989/90 para 43 milhões de toneladas esmagadas em 2018/19. O Brasil inicialmente esmagou 15,75 milhões de toneladas de soja em grãos em 1989/90 e ampliou para 42,7 milhões de toneladas esmagadas em 2017/18, representando um acréscimo de 2 vezes mais no esmagamento de soja no período de análise. 
Figura 7 - Principais países esmagadores de soja no mundo (1000MT): 1990 a 2019

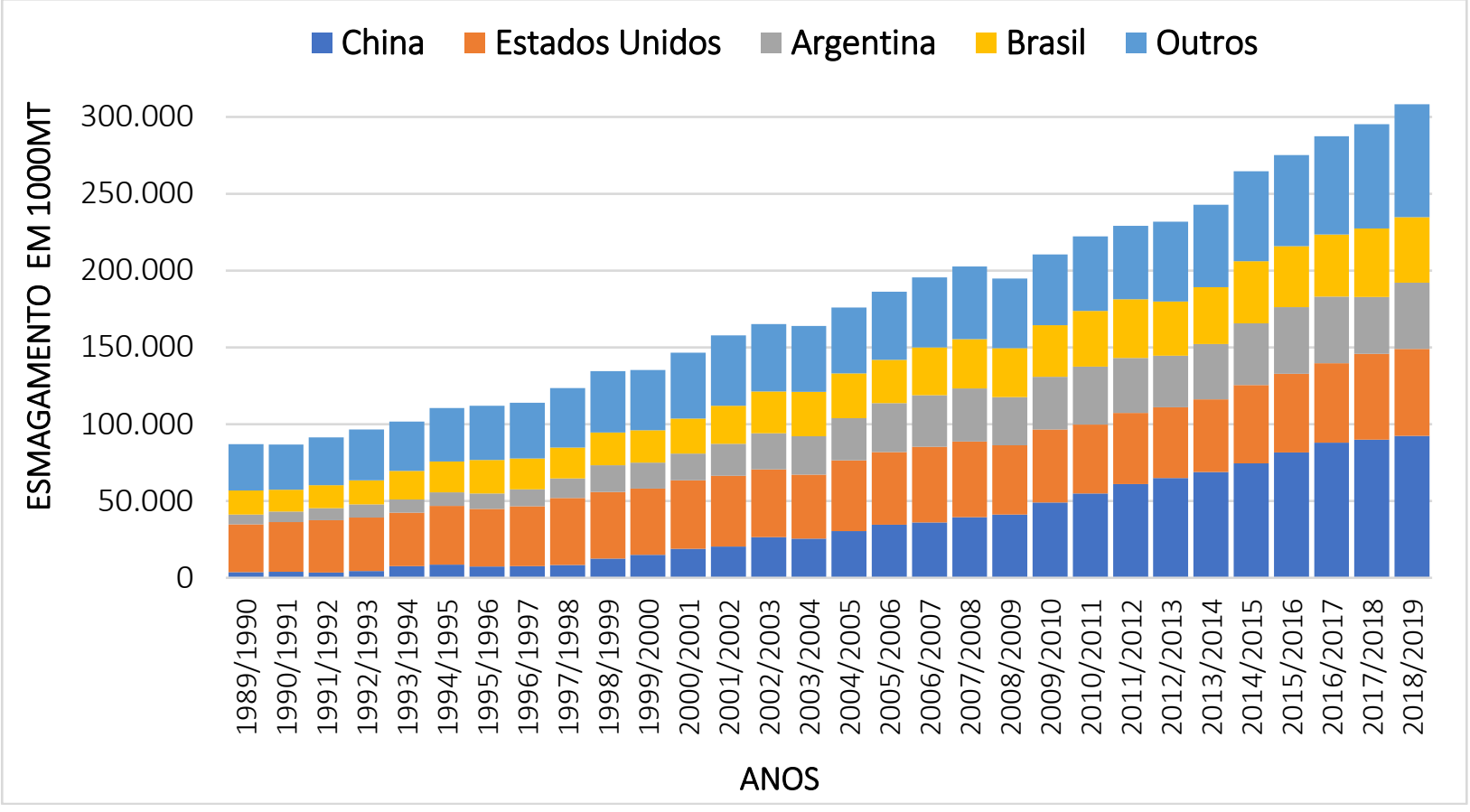

Fonte: Organização do autor com base em USDA (2020).

A Figura 8 evidencia os maiores exportadores de óleo de soja no mundo no período de 1990 a 2019, entre os principais estão Argentina, Brasil e Estados Unidos, enquanto há demais países exportadores de óleo de soja na parcela destinada a outros. Constata-se com a figura que houve uma tendência de crescimento nas exportações destes países, especialmente para Argentina e Brasil. A Argentina obtém a maior parcela do mercado de exportações do óleo de soja, na sequência está o Brasil e Estados Unidos.

A Argentina exportou 994 mil toneladas de óleo de soja em 1989/90 e elevou esse volume para 5,1 milhões de toneladas em 2018/19, resultando a 5 vezes maior de aumento no volume exportado de óleo de soja. E o Brasil, segundo maior produtor de soja no mundo, exportava 866 mil toneladas de óleo de soja em 1989/90 e 1,35 milhões de toneladas em 2018/19, e obteve uma vez mais de aumento e os Estados Unidos, maior produtor de soja no mundo elevou as exportações de 614 mil toneladas em 1989/90 para 998 mil toneladas em 2018/19, e obteve um acréscimo de 62,54\%. Brasil e Estados Unidos são responsáveis pela maior parcela da produção e exportações de soja em grãos, obtiveram aumento de uma vez nas exportações de óleo de soja bem mais baixas que a Argentina. 
Figura 8 - Principais países exportadores de óleo de soja no mundo (1000MT): 1990 a 2019

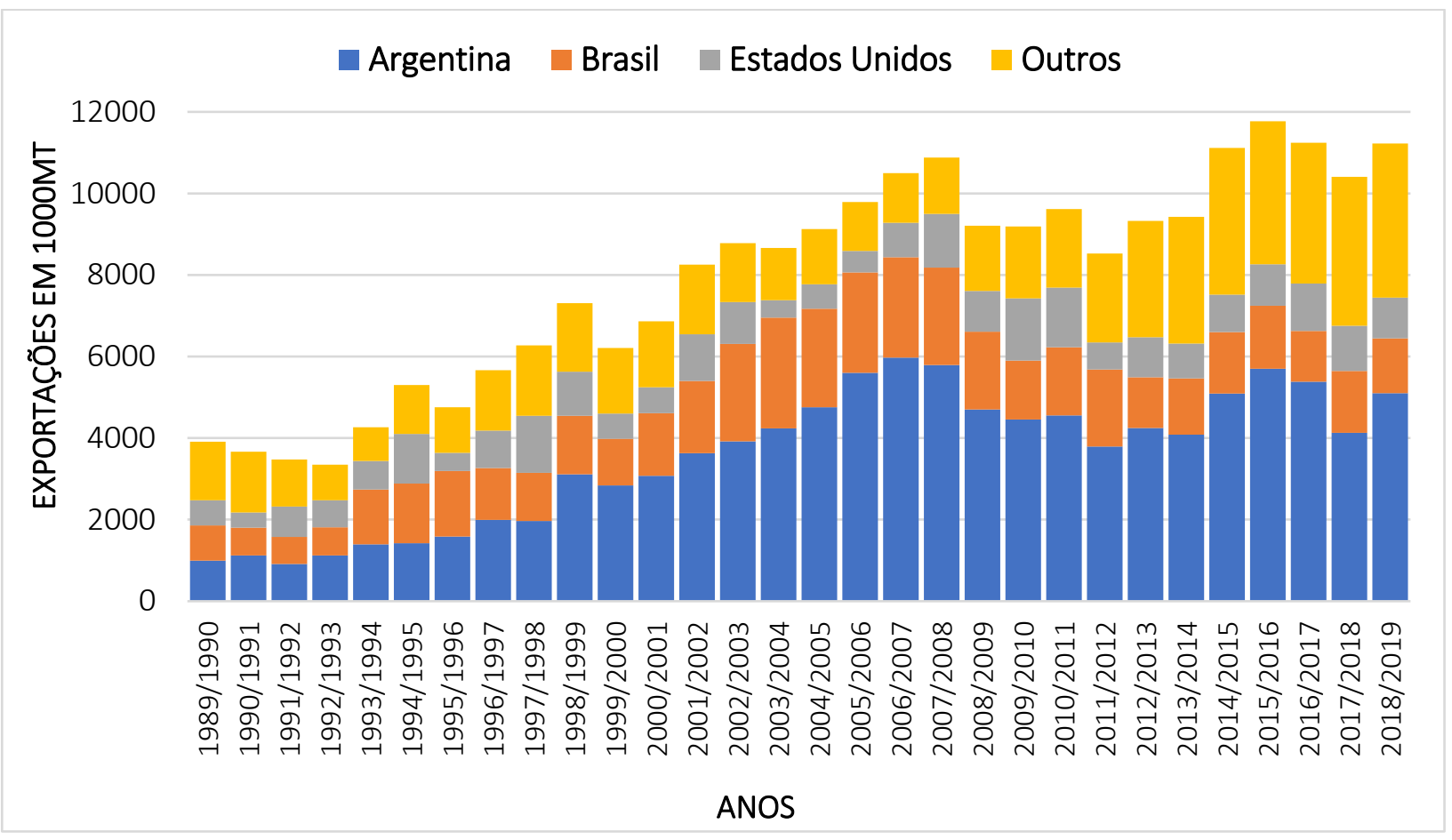

Fonte: Organização do autor com base em USDA (2020).

Na Figura 9, apresenta-se os maiores exportadores de farelo de soja no mundo no período de 1990 a 2019. Verifica-se que os maiores exportadores são Argentina, Brasil, Estados Unidos e os demais países que possuem uma parcela menor de participação nesse comércio. Estes países obtiveram um crescimento ao longo do período de análise, a Argentina foi o país que mais cresceu no comércio internacional de farelo de soja.

A Argentina, maior exportadora de farelo de soja, obteve um aumento de 7 vezes nas exportações de farelo de soja no período de análise, resultado de uma ampliação de 4 milhões de toneladas exportadas em 1989/90 para 29,8 milhões de toneladas exportadas de farelo de soja em 2018/19. Enquanto o Brasil, obteve um crescimento de uma vez, a partir da ampliação de 9,43 milhões de toneladas exportadas em 1989/90 para 15,22 milhões de toneladas exportadas em 2018/19, e os Estados Unidos obtiveram um aumento de 2 vezes nas exportações de farelo de soja a partir de uma elevação de 4,91 milhões de toneladas exportadas em 1989/90 para 12,47 milhões de toneladas exportadas em 2018/19. 
Figura 9 - Principais países exportadores de farelo de soja no mundo (1000MT): 1990 a 2019

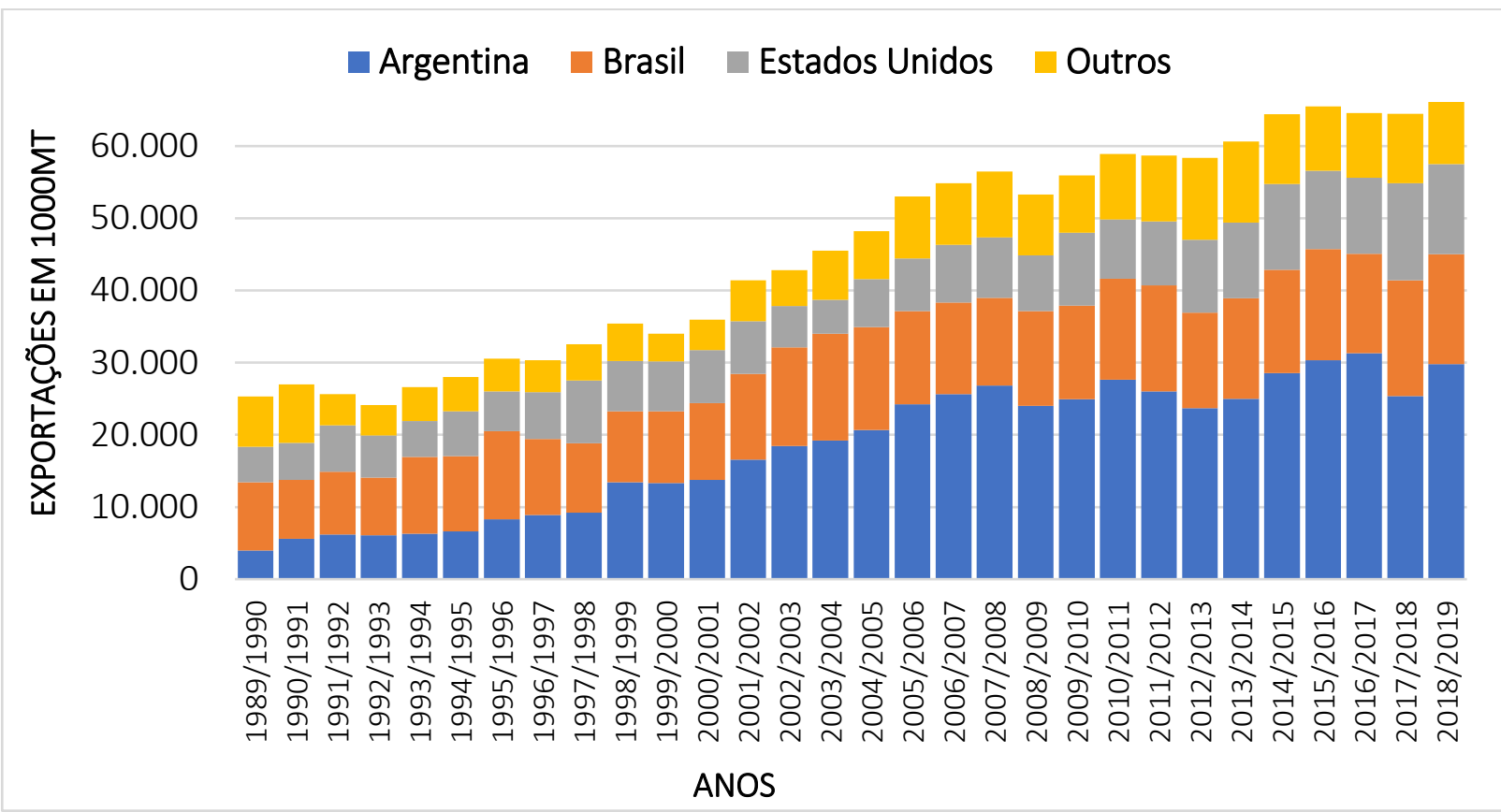

Fonte: Organização do autor com base em USDA (2020).

Destaca-se que a parir desta análise gráfica exposta foi possível identificar e analisar como vem ocorrendo a trajetória e evolução das exportações do complexo soja para o Brasil e Argentina ao longo dos anos, que podem ter sido motivadas por diversos fatores que não serão explorados nesse estudo. Assim para melhor robustez e compreensão, na próxima subseção analisa-se os resultados do modelo econométrico de taxa de crescimento log-linear para Brasil e Argentina.

\subsection{Análise da taxa média de crescimento log-linear para o farelo, óleo e soja em grãos no Brasil e na Argentina}

O objetivo dessa seção é apresentar os resultados estimados pelo modelo econométrico de taxas médias de crescimento log-linear das variáveis estudadas, e dessa forma, conectá-las com as análises dos gráficos. Para tanto o quadro 1 apresenta a taxa média de crescimento loglinear para o farelo de soja, óleo de soja e soja em grãos no Brasil e na Argentina no período de 1990 a 2019.

Observando-se o Quadro 1 pode-se identificar através da equação de regressão log-linear, a qual considera a relação entre a variável ano/safra x exportações de soja em grão no período, que o Brasil possui uma taxa de crescimento anual das exportações de soja em grão de 12,12\%, 
enquanto a Argentina possuí uma taxa de crescimento anual das exportações de soja em grão em 5,15\%. Dentro do período de análise, a diferença nas taxas de crescimento dos dois países, demonstram o nível de expansão nas exportações de soja em grãos por parte do Brasil por diversas razões que não serão exploradas nesse estudo.

Enquanto a relação entre a variável ano/safra x exportações de farelo de soja, o Brasil possui uma taxa de crescimento anual das exportações de farelo de soja de 1,97\% e a Argentina possuí uma taxa de crescimento anual das exportações de farelo de soja de 7,05\%. Neste período de análise, a diferença na taxa de crescimento das exportações de farelo de soja no Brasil e na Argentina evidenciam a maior expansão de processados por parte da Argentina. Da mesma forma ocorre para o óleo de soja, ao observar a equação de regressão log-linear, que considera a relação entre a variável ano/safra x exportações de óleo de soja, que o Brasil possui uma taxa de crescimento anual das exportações de óleo de soja foi de 1,92\%, e a, Argentina possuí uma taxa de crescimento anual das exportações de óleo de soja de 6,16\%.

O mesmo quadro apresenta a equação de regressão log-linear, que considera a relação entre a variável ano/safra x produção e ano/safra x esmagamento, o Brasil possui na produção uma taxa de crescimento anual de $6,90 \%$, e no esmagamento possui uma taxa de crescimento anual de $3,91 \%$. nas exportações de soja em grãos uma taxa de crescimento anual de $12,12 \%$. Quando comparadas com as exportações de soja em grãos brasileiras, verifica-se que o esmagamento obteve o menor crescimento entre as três variáveis e dessa forma, Brasil tem tido uma expansão ao longo do período na produção e consequentemente na exportação de soja em grãos. Com uma taxa geométrica de crescimento anual maior nas exportações (12,12\%) e menor no esmagamento doméstico (3,91\%), conclui-se que o Brasil destina a soja em grãos principalmente para o comércio internacional, e uma parcela menor para esmagamento doméstico. 
Quadro 1 - Taxa média de crescimento log-linear para farelo e óleo de soja e soja em grãos no Brasil e na Argentina no período de 1990 a 2019

\begin{tabular}{|c|c|c|}
\hline Resultados Econométricos & $\begin{array}{l}\text { Antilogaritmo do coeficiente } \\
\qquad b\end{array}$ & $\begin{array}{c}\text { Análise de tendência e } \\
\text { de Taxa geométrica de } \\
\text { crescimento }\end{array}$ \\
\hline \multicolumn{3}{|c|}{ SOJA EM GRÃOS } \\
\hline \multicolumn{3}{|c|}{ BRASIL } \\
\hline$\frac{\ln _{\text {ProduçãoSojaBrasil }} i=9,805974+0,0667 t_{i}}{R^{2}=0,979545 ; F=1389,759}$ & $r=\left[(e)^{0,0667}\right]-1=6,90 \%$ & $\begin{array}{l}\text { Crescente. Taxa geométrica } \\
\text { de crescimento: 6,90\% a.a. }\end{array}$ \\
\hline$\frac{\text { ln EsmagamentoSojaBrasil }_{i}=9,637715+0,0383 t_{i}}{R^{2}=0,964657 ; F=792,5340}$ & $r=\left[(e)^{0,0383}\right]-1=3,91 \%$ & $\begin{array}{l}\text { Crescente. Taxa geométrica } \\
\text { de crescimento: 3,91\% a.a. }\end{array}$ \\
\hline$\frac{\text { In ConsDomestSojaBrasil }_{i}=9,722349+0,037603 t_{i}}{R^{2}=0,962965 ; F=755,0410}$ & $r=\left[(e)^{0,03760}\right]-1=3,83 \%$ & $\begin{array}{l}\text { Crescente. Taxa geométrica } \\
\text { de crescimento: } 3,83 \% \text { a.a. }\end{array}$ \\
\hline$\frac{\text { ln ExpSojaGrãosBrasil }_{i}=8,059189+0,1143 t_{i}}{R^{2}=0,955918 ; F=629,8621}$ & $r=\left[(e)^{0,1143}\right]-1=12,12 \%$ & $\begin{array}{l}\text { Crescente. Taxa geométrica } \\
\text { de crescimento: } 12,12 \% \text { a.a. }\end{array}$ \\
\hline \multicolumn{3}{|c|}{ ARGENTINA } \\
\hline$\frac{\text { In ProduçãoSojaArgentina }_{i}=9,303756+0,0653 t_{i}}{R^{2}=0,854885 ; F=171,8416}$ & $r=\left[(e)^{0,06539}\right]-1=6,76 \%$ & $\begin{array}{l}\text { Crescente. Taxa geométrica } \\
\text { de crescimento: 6,76\% a.a. }\end{array}$ \\
\hline$\frac{\ln \text { EsmagamSojaArgentina }_{i}=8,939707+0,0696 t_{i}}{R^{2}=0,913570 ; F=307,5303}$ & $r=\left[(e)^{0,0696}\right]-1=7,22 \%$ & $\begin{array}{l}\text { Crescente. Taxa geométrica } \\
\text { de crescimento: } 7,22 \% \text { a.a. }\end{array}$ \\
\hline$\frac{\text { ln ExpSojaGrãosArgentina }_{i}=7,857658+0,0501 t_{i}}{R^{2}=0,435530 ; F=23,37562}$ & $r=\left[(e)^{0,0501}\right]-1=5,15 \%$ & $\begin{array}{l}\text { Crescente. Taxa geométrica } \\
\text { de crescimento: } 5,15 \% \text { a.a. }\end{array}$ \\
\hline \multicolumn{3}{|c|}{ FARELO DE SOJA } \\
\hline \multicolumn{3}{|c|}{ BRASIL } \\
\hline$\frac{\text { In ExpFareloSojaBrasil }_{i}=9,111229+0,01951 t_{i}}{R^{2}=0,759808 ; F=92,73678}$ & $r=\left[(e)^{0,0195}\right]-1=1,97 \%$ & $\begin{array}{l}\text { Crescente. Taxa geométrica } \\
\text { de crescimento: } 1,97 \%\end{array}$ \\
\hline \multicolumn{3}{|c|}{ ARGENTINA } \\
\hline$\frac{\text { ln ExpFareloSojaArgentina }_{i}=8,672543+0,0680 t_{i}}{R^{2}=0,888466 ; F=232,0098}$ & $r=\left[(e)^{0,0680}\right]-1=7,05 \%$ & $\begin{array}{l}\text { Crescente. Taxa geométrica } \\
\text { de crescimento: } 7,05 \% \text { a.a. }\end{array}$ \\
\hline \multicolumn{3}{|c|}{ ÓLEO DE SOJA } \\
\hline \multicolumn{3}{|c|}{ BRASIL } \\
\hline$\frac{\ln _{\text {ExpÓleoSojaBrasil }} i=7,020129+0,0190 t_{i}}{R^{2}=0,169556 ; F=6,921065}$ & $r=\left[(e)^{0,0190}\right]-1=1,92 \%$ & $\begin{array}{l}\text { Crescente. Taxa geométrica } \\
\text { de crescimento: } 1,92 \% \text { a.a. }\end{array}$ \\
\hline \multicolumn{3}{|c|}{ ARGENTINA } \\
\hline$\frac{\text { ln ExpÓleoSojaArgentina }_{i}=7,169769+0,0597 t_{i}}{R^{2}=0,757876 ; F=91,77338}$ & $r=\left[(e)^{0,0597}\right]-1=6,16 \%$ & $\begin{array}{l}\text { Crescente. Taxa geométrica } \\
\text { de crescimento: } 6,16 \% \text { a.a. }\end{array}$ \\
\hline
\end{tabular}

Fonte: Elaboração própria (USDA, 2020)

Através da equação de regressão log-linear que considera a relação entre a variável ano/safra e a produção, esmagamento ou exportações de soja em grão no período, a Argentina possui uma taxa geométrica de crescimento anual da produção de soja em grão de $6,76 \%$. 0 
esmagamento doméstico obteve uma taxa de crescimento anual de 7,22\%, enquanto as exportações de soja obtiveram uma taxa de crescimento anual de 5,15\%, representando desta forma que o esmagamento obteve o maior crescimento entre as três variáveis. Com uma taxa geométrica de crescimento anual maior no esmagamento doméstico $(7,22 \%)$ e menor nas exportações $(5,15 \%)$, conclui-se que a Argentina destina a soja em grãos principalmente para o comércio interno de esmagamento, e uma parcela menor para as exportações de soja em grãos.

Analisando-se o quadro de forma comparada de Brasil e Argentina, a diferença na taxa de crescimento da quantidade esmagada de soja em grãos no Brasil (3,91\%) e na Argentina (7,22\%) evidenciam a maior expansão de processados por parte da Argentina. Por fim, evidenciou-se que, nas últimas décadas a Argentina se destaca pelo aumento nas exportações de farelo e óleo de soja, enquanto o Brasil pelo aumento nas exportações de soja em grãos.

\section{Considerações finais}

Este estudo objetivou analisar as trajetórias de exportações de Brasil e Argentina no comércio internacional de soja em grãos, farelo de soja e óleo de soja, para o período de 1990 a 2018. Para isso, utilizou-se o modelo econométrico de taxa de crescimento calculado a partir das exportações de soja em grãos, farelo e óleo de soja de Brasil e Argentina para o período de 1990 a 2018.

Constatou-se que ao longo das últimas décadas, a soja tornou-se a principal atividade agropecuária no Brasil e na Argentina, em termos territoriais e econômicos comerciais. Os dois países apresentaram resultados diferentes nas exportações do complexo soja e boa parte dessas diferenças podem ser atribuídas as diversas condições de cada país em vantagens comparativas e competitivas que podem ser exploradas em estudos futuros.

Os resultados estimados com o modelo econométrico de taxa de crescimento log-linear nos mostra de forma comparada que a Argentina apresentou uma taxa de crescimento anual maior nas exportações de farelo de soja 7,05\% e óleo de soja 6,16\%, enquanto a taxa geométrica de crescimento das exportações de soja em grãos representou 5,15\%, no consumo doméstico a Argentina obteve uma taxa de crescimento anual de 7,22\%. Já o Brasil, obteve uma taxa de crescimento maior nas exportações de soja em grãos $12,12 \%$, enquanto as exportações de farelo de soja e óleo de soja representaram respectivamente, 1,97\% e 1,92\%, e no consumo doméstico obteve uma taxa geométrica de crescimento de $3,91 \%$. 
Por fim, o modelo econométrico de taxa de crescimento permitiu analisar o cenário de exportações de Brasil e Argentina e concluir que nas últimas décadas a Argentina se destacou pelo aumento nas exportações de farelo e óleo de soja, enquanto o Brasil pelo aumento nas exportações de soja em grãos, o que evidencia trajetórias de exportação antagônicas.

Para estudos futuros recomenda-se a inclusão dos Estados Unidos na análise, devido a sua representatividade no mercado internacional da soja e a exploração dos fatores que motivam essas diferenças.

\section{Referências}

CALDARELLI, C. E.; GABARDO DA CÂMARA, M. R.; SEREIA, V. J. O complexo agroindustrial da soja no Brasil e no Paraná: exportações e competitividade no período 1990 a 2007.

Organizações Rurais \& Agroindustriais, vol. 11, núm. 1, pp. 106-120, janeiro-abril, 2009.

CÁMERA DE LÁ INDÚSTRIA ACEITERA DE LA REPÚBLICA ARGENTINA (CIARA). Consulta de Evolución de los Aranceles de Exportación, 2020. Disponível em:<http://www.ciaracec.com.ar/ciara/Estad\%C3\%ADsticas/Evoluci\%C3\%B3n\%20de\%20los\%2 OAranceles\%20de\%20Exportaci\%C3\%B3n> Acesso em 27 de janeiro de 2020.

COSTA, N. L.; SANTANA, A. C. de. Poder de mercado e desenvolvimento de novas cultivares de soja transgênicas e convencionais: análise da experiência brasileira. Rev. Cienc. Agrar., v. 56, n. 1, p. 61-68, jan./mar. 2013.

FIGUEIREDO, A. M.; SANTOS, M. L. Evolução das vantagens comparativas do Brasil no comércio mundial de soja. Revista Política Agrícola, ano XIV, no1, jan./fev./mar. 2005.

GUJARATI, D. Econometria básica. Rio de Janeiro: Elsevier. 3a ed., 2006.

GUJARATI, D. N.; PORTER, D. C.. Econometria Básica. São Paulo, ed. AMGH Editora Ltda 5ed. 2011.

HINRICHSEN, J. J. Annual Yearbook on Oilseeds Markets. Buenos Aires, 2013.

MINISTÉRIO DA AGRICULTURA PECUÁRIA E ABASTECIMENTO (MAPA). Estatísticas de Comércio Exterior do Agronegócio Brasileiro - Plataforma AGROSTAT. Disponível em:

<http://sistemasweb.agricultura.gov.br/pages/AGROSTAT.html> Acesso em 22 de janeiro de 2020.

RICHARDSON, N. P. Export-Oriented Populism: Commodities and Coalitions in Argentina. Journal Springer, St Comp Int Dev, 44:228-255, 2008.

SAMPAIO, L. M. B.; SAMPAIO, Y.; BERTRAND, J. P. Fatores determinantes da competitividade dos principais países exportadores do complexo soja no mercado internacional. Revista Organizações Rurais \& Agroindustriais, Universidade Federal de Lavras Minas Gerais, Brasil, vol. 14, núm. 2, pp. 227-242, 2012.

SANTANA, A. C. de. Métodos quantitativos em economia: elementos e aplicações. Belém: UFRA, 2003. 
UNITED STATES DEPARTMENT OF AGRICULTURE (USDA). Foreign Agricultural Service. Disponível em: <https://apps.fas.usda.gov/psdonline/app/index.html\#/app/home> Acesso em 15 de dezembro de 2019.

UNITED STATES DEPARTMENT OF AGRICULTURE (USDA). World Agricultural Supply and Demand Estimates, 2016. Disponível em:<https://usda.mannlib.cornell.edu/MannU sda/viewDocumentInfo.do?documentID=1194> Acesso em 15 de dezembro de 2019. 